\title{
Preparation of feed mixtures by the combined blender
}

\author{
Chernovol M \\ a corresponding member of the NAAS of Ukraine, Doctor of Technical Sciences \\ Sviren $\mathbf{M}$. \\ Doctor of Technical Sciences \\ Kisiliov R. \\ Candidate of Technical Sciences \\ Central-Ukrainian national technical university,
}

The purpose. To raise quality and to improve the process of mixing together of feedstuffs due to application of new construction of the blender, to justify its rational parameters. Methods. Theory of mathematical simulation, bases of use of machinery in animal husbandry. Results. The computational model of operation of mechanically-technological scheme of the combined blender and mathematical model of dynamic interaction of agitator blades with feed monolith is developed. It is established that technological efficiency of preparation of uniform mix depends on physicomechanical properties of its ingredients, influence and interaction of the shape and geometrical parameters of attacking surface of blades, angle of inclination, step of device and operating conditions of the blender. Conclusions. Results of probes confirm an opportunity of heightening efficiency of technique of preparation of high-grade balanced feed mixtures for cattle by intensification of process of mixing together with application of construction of the combined belt-blade blender.

Key words: blender of feedstuffs, feedstuffs, animal husbandry, blade mixer, feed mixtures, zootechnical demands.

Increase in efficiency of branch of livestock production significantly depends on quality of preparation of forages as they in structure of product cost put $30-60 \%$ of expenses [1-3]. Progressive technologies which allow to realize fully the genetic potential of animals due to the lack of necessary technical providing were not widely adopted.

The existing designs of mixers of forages for cows not completely provide zootechnical requirements to preparation of the multicomponent balanced fodder mixes, have heavy power expenses and high specific capacity of material. Therefore the researches directed to development of workers of bodies for mixers of forages which will provide creation of a highly effective food supply at low power consumptions and materials have economic value [4-6].

The purpose of researches is upgrading and improvement of technological process of mixing of forage due to application of new construction of mixer and ground of it rational parameters.

Methods of researches. During the leadthrough of theoretical researches used the methods of theory of mathematical design, bases of the use of machines, in a stock-raising.

Results of researches. The duty cycle of traditional mixers of batch-type consists of such successive operations: load of the proper doses of components ( straw, root crops, sterns, and others like that), interfusion of them and unloading of the prepared mixture, auger for unloading, after it a cycle repeats oneself. In the mixers of batch-type homogeneity of mixture is regulated duration of process of mixing.

The analysis of quality indicators of operation of the existing mixers confirms insufficient stability and complexity of process: components move in the bunker unevenly, and the uniformity of mixing does not meet the established requirements. For ensuring technological process of mixing it is necessary a long time (more than 10.15 min.) on bringing mix to homogeneous mass which reduces productivity and increases power consumptions [7-9]. 
For elimination of the existing shortcomings of traditional mixers the advanced mixer with the combined scheme of the movement of raw materials multisection screw, tape and flat blades (fig. 1) is offered.

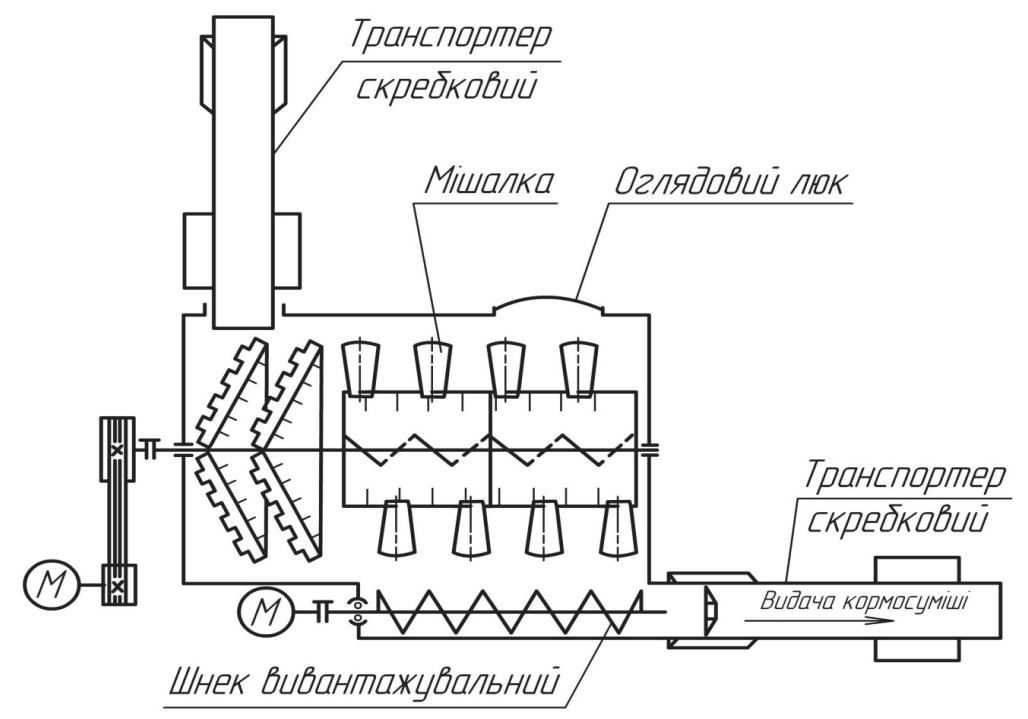

Fig. 1. Technological scheme of the tape and bladed mixer of forages

For an intensification of process and increase dynamic mixing of components in microvolumes equipped additionally screw and flat blades with radial blades.

Process of mixing of forages the advanced mixer is carried out thus. The corresponding doses of components of mix are layer-by-layer loaded by the combined conveyor into the bunker, their stream with simultaneous mixing of raw materials tape long screw blades with fingers is gradually leveled move in the multisection mixer with flat blades (fig. 2) further. Blades of the top row with the right tilt angle separate a portion of mix on width of the blade and move in the radial, circular and axial direction to the right end of the mixer, and the second row, with the left tilt angle, to the left end of the mixer, creating a big microvolume set of mix with discrete contents of parts of the mixing components together with radial fingers. At the same time, parts of everyone to a component of mix get to the area of interaction of difficult movements, crossings and collisions and periodically move from one stream to another that provides an intensive mass exchange and accelerates process of mixing of forages.

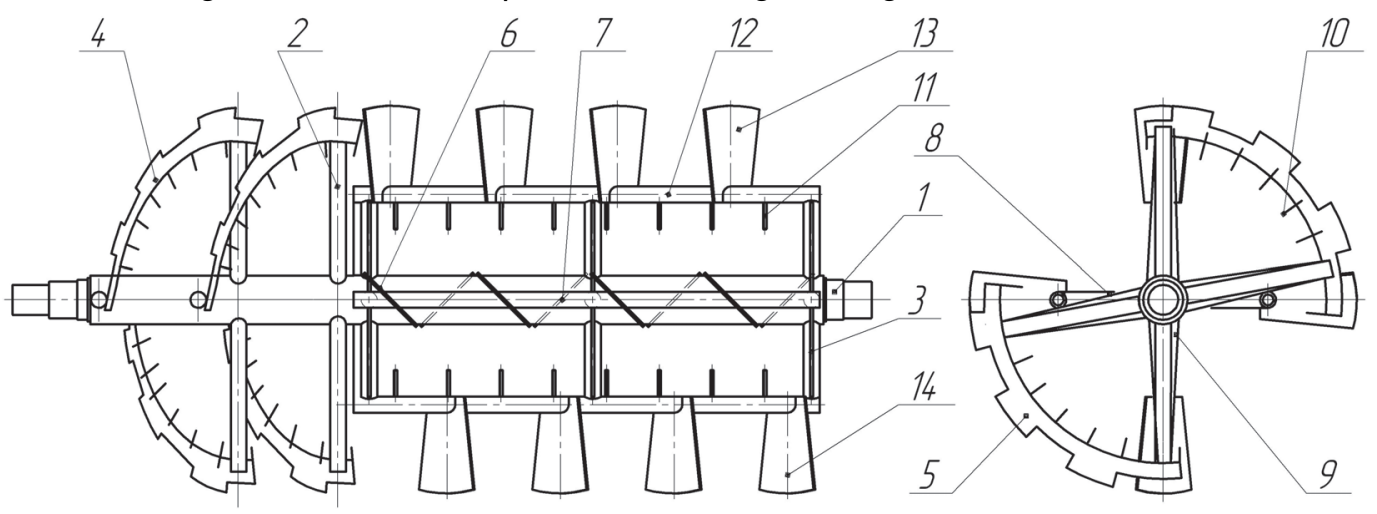

1 - shaft; 2 - stand of the screw mixer; 3 - scoop of the blade mixer; 4, 5 - screw ribbon; 6, 7 - left blade; 8 - a rack of a shovel stirrer; 9 - scython screw mixer; 10, 11 - radial fingers; 12 - horizontal pipe; 13, 14 - the right to blade

Fig.2 Technological scheme of the advanced combined mixer

Moving the feed mixture on the surface of blades with different angles in the zone of inertial (free) motion is carried out in the mode of increased process dynamics and increased number of collisions and 
cross sections in the radial and axial direction, which is determined by the shape and size of the attacking blade, the step of their location, angle of inclination and kinematics the modes of blades (Fig. 3).
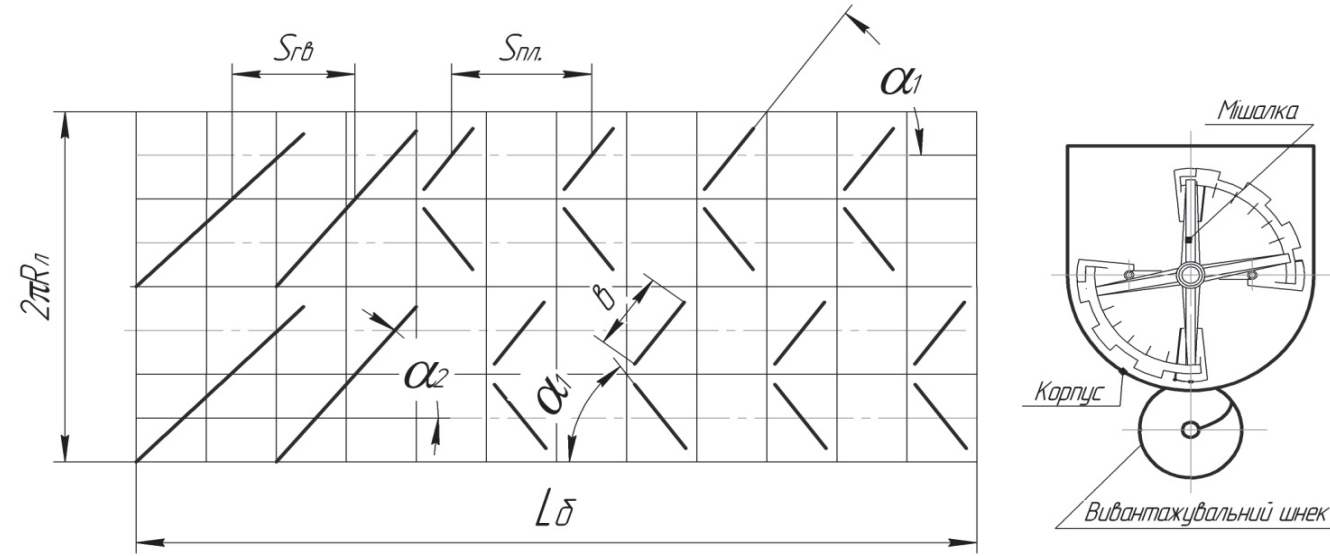

Fig. 3. Scheme of location of screw and flat blades with different direction of their inclination to the axis, installed on the periphery

The determination of the kinematics of the motion of the mixture fraction was carried out taking into account frictional forces and the angle of the blades $[10,11,12]$. In the presence of friction, depending on the angle of the blade to the axis of the shaft, the displacement of the material point of the component of the mixture in the axial direction occurs during the passage of the blade by the value (Fig. 4).

$$
h_{o}=S \cdot \frac{\cos \alpha \cos (\alpha+\varphi)}{\cos \varphi},
$$

lags in the axial direction by magnitude:

$$
Z_{o}=S \cdot \frac{\sin \alpha \sin (\alpha+\varphi)}{\cos \varphi},
$$

lags in a circular direction:

$$
\lambda=S \cdot \frac{\cos \alpha \cdot \sin (\alpha+\varphi)}{\cos \varphi},
$$

where $\alpha$ - angle of inclination of the blade;

$\varphi$ - the angle of friction of the particle on the surface of the blade;

$S$ - projection of the width of the blade.

The axial velocity of the displacement of a particle of a mixture is determined from the expression:

$$
\vartheta_{0}=S \cdot(1-\mu)=S \cdot\left[1-\frac{\sin \alpha \cdot(\sin \alpha+\varphi)}{\cos \varphi}\right] \text {, }
$$

where - the coefficient of axial lagging of particles depending on the angles $\alpha$ and $\varphi$.

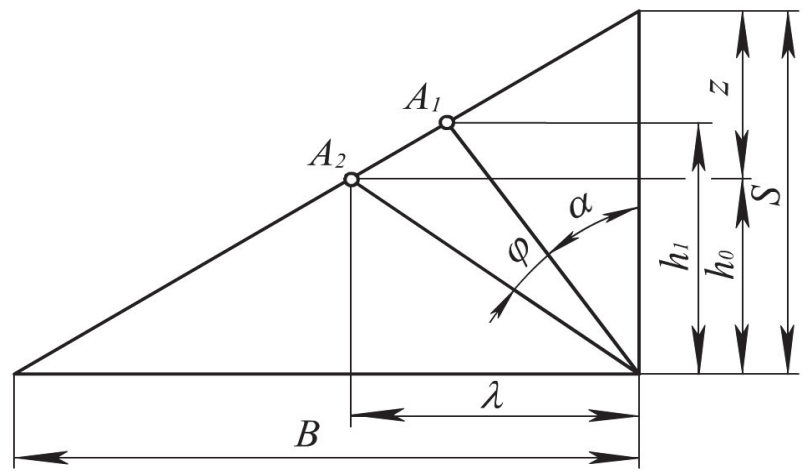

Fig. 4 Movement of the material part in the axial direction during the passage of its blade 
The analysis of equations (1), (2) and (4) shows that the displacement of the particles of the mixture in the axial direction and the axial velocity of their movement depends on the angle of the blades to the shaft axis of the mixer $\alpha$, the friction angle of the mixture on the surface of the blade and the coefficient of axial lag of material particles mixtures (Fig. 5, 6).

With the increase of the angle $\alpha$ with constant friction coefficient, the axial lag of the displacement of the particles of the mixture decreases, and at a constant angle of inclination of the blade $\alpha$ with an increase in the coefficient of friction, the axial lag increases and the axial velocity of their movement decreases.

For flat blades with a slope, dead zones appear at a friction coefficient that does not meet the technological requirements for mixing feed, and discrete particles have only rotational motion.

In the course of the motion of the mixer, separating the mixture with the blades, the particles receive a pulse from the radial and normal forces $P_{p}^{\prime}=P_{H} \cdot \cos \alpha$ and $P_{o}^{\prime}=P_{H} \cdot \sin \alpha \quad(\alpha-$ the angle of the blade to the axis of rotation of the shaft).

In addition, under the action of the normal component of the force $\mathrm{R}$ in the plane of motion of particles on the blade there is a friction force $F=f \cdot P_{H}$ directed against the relative motion of particles along the blade. Friction $\mathrm{F}$ is decomposed into circular and axial components:

$$
\begin{array}{r}
F_{p}^{\prime}=F \cdot \sin \alpha=f \cdot P_{H} \cdot \sin \alpha, \\
F_{o}^{\prime}=F \cdot \cos \alpha=f \cdot P_{H} \cdot \cos \alpha .
\end{array}
$$

Taking into account the obtained vectors in directions of motion, we obtain circular and axial efforts:

$$
\begin{aligned}
& P_{p}=P_{p}^{\prime}+F_{p}^{\prime}=P_{H} \cdot(\cos \alpha+f \cdot \sin \alpha), \\
& P_{o}=P_{o}^{\prime}+F_{o}^{\prime}=P_{H} \cdot(\sin \alpha-f \cdot \cos \alpha) .
\end{aligned}
$$
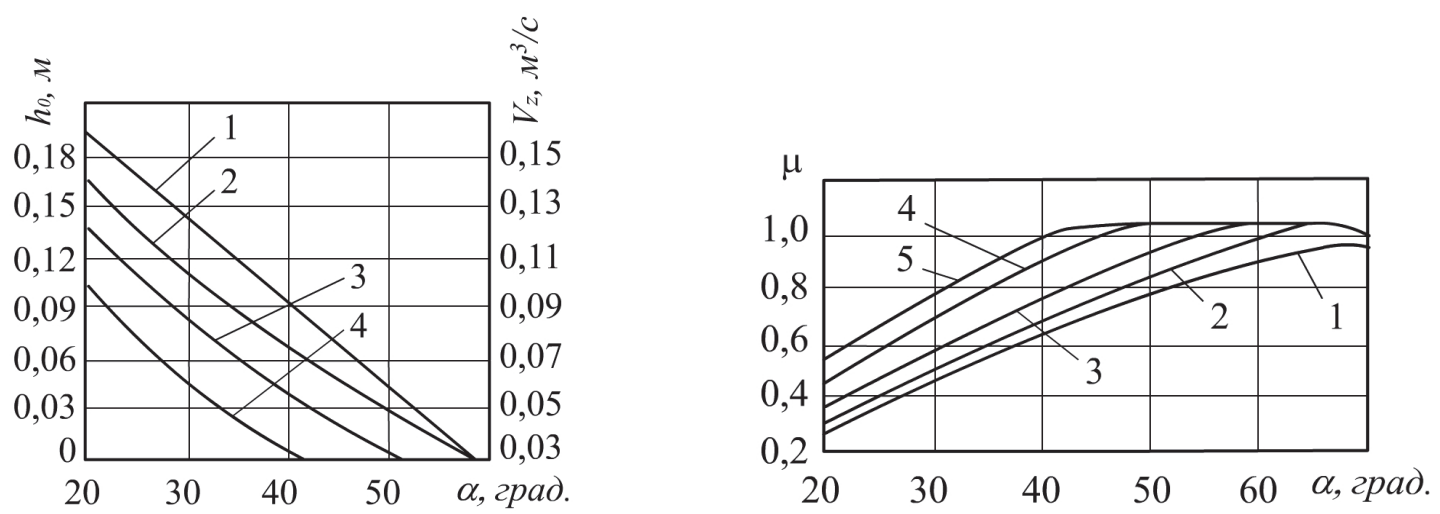

1 - velocity $V_{z}$ for $f=0,4 ; 2,3,4$

$1-f=0,4 ; 2-f=0,51 ; 3-f=0,7$

- axial displacement $h_{0}$ at $f=0,4$;

$f=1,0 ; 4-f=1,2 ; 5-f=1,73$

0,$7 ; 1,2$ respectively

Fig. 5. Dependence of the value of

the axial displacement $h_{0}$ and the

Fig. 6. Dependence of the coefficient

axial velocity $V_{z}$ of the particles

of the mixture from the slope

of the axial lag of the particles

of the mixture on the angle $\alpha$

angle of the blades $\alpha$

and the coefficient of friction $f$.

In the case of incomplete filling of the hopper mixer normal component $P_{H}$ is determined by the formula: 
$P_{H}=9,81 \gamma \cdot h_{\text {cep. }} \cdot F_{\pi} \cdot \operatorname{tg}^{2} \cdot\left(45+\frac{\varphi}{2}\right)$,

Where $h_{\text {cep. }}$ - the average depth of the largest depression of the blade, m;

$F_{n}$ - projection of the blade area on the direction of rotation of the mixer,

$\varphi$ - angle of internal friction, degrees;

$\gamma$ - bulk density of the mixture, $\mathrm{kg} /$

The required drive power of the blades of the mixer is determined by the expression, $\mathrm{kW}$ :

$N_{л}=\frac{1}{1000} \cdot\left(P_{p} \mathrm{v}_{p}+P_{o} \mathrm{v}_{o}\right) \cdot Z_{л}$

where $Z_{\pi}$ - the number of blades that are simultaneously immersed in the feed mix.

Thus, the total power of the stirrer mixer actuator is determined by:

$N_{\mathrm{м}}=N_{\text {гл }}+N_{n л}+N_{\text {гсm }}+N_{n c m}+N_{n}+N_{\text {гор.mp. }}+N_{f}+N_{\eta_{M}}$,

$N_{2 n}, N_{n n}, N_{\text {ccm }}, N_{n c m}, N_{n}, N_{\text {cop.mp. }} N_{f}, N_{\eta_{u}}$ - power consumption on the drive, respectively, screw and flat blades, screw and flat scoops, radial fingers, horizontal tubes, friction of the mixer from the housing and shaft bearings, $\mathrm{kW}$.

Power on screw and flat blade drive:

$$
N_{2 \pi}=\frac{P_{p} \vartheta_{p}+P_{o} \vartheta_{o}}{10^{3}} \cdot Z_{л}
$$

where $P_{p}, P_{o}$ is circular and axial effort, $\mathrm{H} ; \vartheta_{p}, \vartheta_{o} \quad$ it is a circular and axial rate of movement of mixture, mcode/s; $Z_{л}$ it is an amount of the simultaneously submerged blades. Power is on the occasion of bars of spiral and flat blades

$$
N_{c m}=\frac{M_{c m} \cdot Z_{c m} \cdot \omega}{10^{3}}
$$

where $M_{c m}$ - torque from the strength of the resistance of the rack;

$$
M_{c m}=g \cdot l \cdot \frac{R}{2} \cdot h_{c e p .} \cdot a \cdot \gamma \cdot \operatorname{tg} \varphi, H \cdot M,
$$

Where $l$ - the length of the rack, $\mathrm{m} ; \frac{R}{2}$ - the length of the rack to the strength of the resistance, $\mathrm{m}$; $h_{\text {cep. }}$ - average depth of immersion of a rack in a monolith of a feed, $\mathrm{m}$;

$a$ - width of the rack, m;

$\varphi$ - angle of inclination of feed, hailstones;

Power on radial finger drive, $\mathrm{kW}$ :

$$
N_{n}=\frac{M_{n} \cdot Z_{n} \cdot \omega}{10^{3}},
$$

where $M_{n}$ - torque from the strength of the finger resistance, $H \cdot M$;

$$
M_{n}=P_{n} \cdot l_{n} \cdot d_{n} \cdot R_{n}
$$


where $P_{n}$ - the resistivity of the mix, $H / M^{2}$;

$l_{n}$ - the length of a finger, $\mathrm{m}$;

$d_{n}$ - diameter of a finger, $\mathrm{m}$;

$R_{n}$ - average radius of rotation of fingers, $\mathrm{m}$.

Power on the occasion of horizontal pipes, kW:

$$
\begin{aligned}
& N_{\text {гоp.mp. }}=\frac{M_{m p} \cdot Z_{m p} \cdot \omega}{10^{3}}, \\
& M_{m p}=P_{n} \cdot L \cdot d_{m p} \cdot R_{m p} .
\end{aligned}
$$

where $M_{m p}$ - moment from the strength of the resistance of the horizontal pipe, $H \cdot M$;

\section{Conclusions}

The results of the conducted research confirm the possibility of increasing the efficiency of the technology of preparation of complete balanced balanced forage for cattle by intensifying the mixing process with the use of the design of the combined ribbon blade mixer, developing the theoretical basis for the interaction of feed components with its working organs and justifying their main structural and technological parameters. The proposed mixer design ensures homogeneity of the mixture $V_{0}=95 \ldots 98 \%$ and the required technological efficiency and reliability of the process with minimal energy consumption, which corresponds to the current zootechnical requirements $\left(V_{0}=90 \ldots 92 \%\right)$ to homogeneity in the preparation of complete mixtures for cattle.

\section{Bibliography}

1. Kravchuk V., Lutsenko M., Mechta M. (2008). Progressive harvesting technologies, preparation and distribution of feed. Kyiv: Phoenix. 104 p. [In Ukrainian].

2. Lazarevich A.P. (2007). One-type fodder mixes for dairy cattle. Livestock breeding of Ukraine. No. 4. P.- 33-35. [In Ukrainian].

3. Adgidzi D., Mu'azu A., Olorunsogo S.T., Shiawoya E.L. (2006). Design considerations ofmixerpelleting machine for processing animal feeds. 7th annual engineering conference, School of Engineering and Engineering Technology, FUT Minna. $28-30$ June. 3 p.

4. Khmelevsky V.S. (2017). Estimation of uniformity mixing of feeds. Collection of abstracts of reports of the XII International scientific and practical conference "Obukhiv Readings" (March 21, 2017) National University of life and environmental sciences of Ukraine. Kyiv, 2017. P. 77-78. [In Ukrainian].

5. Revenko I., Revenko Yu. (2013). Quality of cooking and efficacy use efficiency is concentrated and Combined Forages. MOTROL. - Lublin-Rzeszow. V. 15, No. 3. P. 356 - 361. [In Russian].

6. Shevchenko I.A., Pavlichenko V.M., Lihodid V.V., Zabudchenko V.M. (2013). Analysis constructions of technical means for production of moist highly digestible fodder. Design, manufacture and operation of agricultural machines: national interdepartmental scientific and technical collection. Kirovohrad: KNTU, 2013. Issue 43. Part 1. P. 179 - 185. [In Ukrainian].

7. Revenko I.I., Braginets M.V., Rebenko V.I. (2009). Machines and equipment for animal husbandry. Kyiv: Condor. 730 p. [In Ukrainian].

8. Shatsky V.V., Milko D.A., Boltyansky B.V. and oth. (2013). The quality of the mixing of the components of the diet - the basis increase in animal productivity. Tavriya State Agrotechnological University. Melitopol: TDATU. Issue 1. Volume 3. P. 43 - 50. [In Ukrainian].

9. Zavrazhnov A.I., Nikolaev D.I. (1990). Mechanization of cooking and storage of fodder. Moskva: Agropromizdat. 336 p. [In Russian]. 
10. Shatsky V.V. (2012). Mathematical modeling dynamics of the density and quality of the feed mixture for animals. Scientific bulletin of Tavriya State Agrotechnological University. Issue 2. Volume 2. P. 3 - 19. [In Russian]

11. Shabelnik B.P., Troyanov M.M. (2002). Theory and calculation of machines for animal husbandry. Kharkiv National Technical University of Agriculture, $216 \mathrm{p}$. [In Ukrainian].

12. Marchenko A.Yu., Serga G.V., Frolov V.Yu., Sysoev D.P. (2013). Mechanic-technological substantiation process of mixing concentrated feed with cylindrical screw drums: monograph. Krasnodar. 112 p. [In Russian]. 